\title{
Learning of Pseudowords by Children of Different Ages in a Shared Book Reading Context
}

\author{
Aline Melina Vaz ${ }^{1}$ (1) https://orcid.org/0000-0002-6104-7975 \\ Andréia Schmidt $^{1}$ (1) https://orcid.org/0000-0002-8836-6618
}

\begin{abstract}
Shared book reading favors incidental learning of vocabulary; however, studies indicate that the previous vocabulary level of the child interferes with learning. The aim of this study was to compare the learning relations between pseudowords and figures of children aged 3 and 7 years in a shared book reading situation and to investigate the possible occurrence of the Matthew Effect. A book with four pseudowords developed for this study was read three consecutive times to 10 children of each age group. Matchingto-sample, exclusion, naming, and description of the use probes were applied immediately after the reading and one week later. No significant differences were found between the performances of both groups, except for the exclusion probes, without incidence of the Matthew Effect. Learning words is a continuous process that involves frequency and contexts of exposure to the words.
\end{abstract}

Keywords: word recognition, vocabulary, behavior analysis, children

\section{Aprendizagem de Pseudopalavras por Crianças de Diferentes Idades em Contexto de Leitura Compartilhada de Livros}

\begin{abstract}
Resumo: A leitura compartilhada de histórias favorece a aprendizagem incidental de vocabulário, mas estudos indicam que o nível de vocabulário prévio da criança interfere nessa aprendizagem. O objetivo deste estudo foi comparar a aprendizagem de relações entre pseudopalavras e figuras por crianças de 3 e 7 anos em situação de leitura compartilhada de histórias e a possível ocorrência do Matthew Effect. Um livro especialmente elaborado para esta pesquisa foi lido por três vezes consecutivas para 10 crianças de cada grupo etário, apresentando quatro pseudopalavras. Sondas de emparelhamento ao modelo, exclusão, nomeação e descrição da utilidade foram aplicadas logo após a leitura e uma semana depois. Não foram encontradas diferenças significativas entre os desempenhos dos dois grupos, exceto nas sondas de exclusão, sem o registro de ocorrência do Matthew Effect. A aprendizagem de palavras é um processo contínuo e envolve condições como a frequência e os contextos de exposição às palavras.
\end{abstract}

Palavras-chave: reconhecimento de palavras, vocabulário, análise do comportamento, crianças

\section{Aprendizaje de Pseudopalabras en Niños de Diferentes Edades en Contexto de Lectura Compartida de Libros}

Resumen: La lectura compartida de libros favorece el aprendizaje incidental de vocabulario; sin embargo, los estudios apuntan que el nivel de vocabulario previo del niño interfiere en este aprendizaje. El presente estudio buscó comparar el aprendizaje de relaciones entre pseudopalabras y figuras en niños de entre 3 y 7 años en situación de lectura compartida de cuentos, así como la posible ocurrencia del Matthew Effect. Un libro no comercial se leyó tres veces consecutivas a 10 niños de cada grupo de edad, presentándoles cuatro pseudopalabras. Se aplicaron pruebas de igualación a la muestra, exclusión y denominación inmediatamente después de la lectura y una semana después de la misma. No se hallaron diferencias significativas en los desempeños de ambos grupos, a excepción de las pruebas de exclusión, y no se registró la ocurrencia del Matthew Effect. El aprendizaje de palabras es un proceso continuo e involucra condiciones como la frecuencia y los contextos de exposición a las palabras.

Palabras clave: reconocimiento de palabras, vocabulario, análisis conductual, niños

${ }^{1}$ Universidade de São Paulo, Ribeirão Preto-SP, Brazil

Study derived from the master's thesis of the first author, under the supervision of the second, defended in 2015, in the Graduate Program in Psychobiology at Universidade de São Paulo.

Support: This study was supported by São Paulo Research Foundation (FAPESP grant \# 2014/22990-5) It is also part of the scientific program of Instituto Nacional de Ciência e Tecnologia Sobre Comportamento, Cognição e Ensino (CNPq \#465686/2014-1 and Fapesp \#2014/50909-8).

Correspondence address: Aline Melina Vaz. Universidade de São Paulo. Faculdade de Filosofia, Ciências e Letras de Ribeirão Preto, Av. Bandeirantes, 2900, Ribeirão Preto-SP, Brazil. CEP 14.040-900. E-mail: alinemelinavaz@gmail.com.
Story reading is an activity that promotes incidental language learning in different cultures, in both the family and school environments (Bus, Leseman, \& Keultjes, 2000; Farrant \& Zubrick, 2013; Zucker, Cabell, Justice, Pentimonti, $\&$ Kaderavek, 2013). Various studies have argued that shared book reading plays an important role in the development of a range of skills, including vocabulary (Blewitt \& Langan, 2016; Farrant \& Zubrick, 2013; Fontes \& Cardoso-Martins, 2004; Hindman, Skibbe, \& Foster, 2014). 
Vocabulary learning during story reading can be influenced by the text itself, such as the number of occurrences of the unknown word, the clues presented in the context, and the importance of the unknown word to the understanding of the context, among others. In addition, authors such as Robbins and Ehri (1994) highlight that the size of the child's previous vocabulary (receptive and expressive) also affects vocabulary acquisition: the larger the vocabulary of the child, the more he/she has learned from story-reading. Such a phenomenon is known as the Matthew Effect in the literature, a term first used by Stanovich (1986) in a review about reading ability. According to some studies, individual differences in reading skills may accumulate over time, so that a child's initial reading level would be positively related to the rate of growth in a reading skill (Duff, Tomblin, \& Catts, 2015).

This cumulative effect has been documented by some authors in studies on the learning of name-figure relations from shared book reading. For example, Robbins and Ehri (1994) conducted a study with 6-year-old children, who were classified into three groups according to their previous level of receptive vocabulary (low, medium and high). The children in the high vocabulary group actually learned a greater number of word-figure relations than the children in the other groups. The study by Wilkinson and Houston-Price (2013) compared the learning of new word-figure relations by children aged 6 and 9 years from story-reading. The previous receptive vocabulary size of the participants was assessed and ranked as "more vocabulary" and "less vocabulary," and the results of the study indicated that older children and children who had larger vocabulary had a better performance, and that these two variables had an additive effect. Similar results were found by Sénéchal, Thomas, and Monker (1995), in a study with 4-year-old children. The authors found that children with more receptive vocabulary, who participated in reading conditions that allowed active participation (pointing to figures or answering questions) spoke more words in expressive tests and identified figures with greater accuracy in receptive tests than those with less vocabulary and who participated in less active reading conditions.

However, other studies on shared book reading have not documented the Matthew Effect, neither in structured reading interventions to promote new vocabulary learning (Hassinger-Das et al., 2016), nor in intensive interventions with story reading (Pollard-Durodola et al., 2011). These discrepant results indicate that, in studies with commercial books (using unusual words from the current vocabulary of the community to which the child belongs), it is difficult to control critical variables that affect vocabulary learning by the children, such as the degree of familiarity with the word and additional exposures of the child to the words out of the reading situation. Furthermore, when studying a homogeneous sample of children according to age, but with differences in the vocabulary level (although without indications of more serious problems of language delay), many other important factors for the development of verbal repertoires are not controlled/known. These factors range from the quantity, quality and diversity of vocabulary to which children are exposed to the regular interactions children have with their family and school community (Hart \& Risley, 1995).

Thus, this study investigated the learning relations between words and figures from shared reading by comparing the performance of children in two different age groups ( 3 and 7 years) and using pseudowords rather than actual words. The age range considered the fact that children aged 3 and 4 years, on average, have vocabulary of up to 1,000 words, while the vocabulary of 7-year-olds is over 10,000 words (Vitto \& Feres, 2005). Given these differences and considering what the literature presents regarding the Matthew Effect, it is possible to assume that, in story-reading situations, older children would learn a greater number of new word-figure relations than younger children due to their better established verbal repertoire and more extensive exposure to their verbal community and to the regularities in language.

The use of pseudowords (invented words, without a conventional meaning in the language) would control the effect of the children's previous history with unknown words, guaranteeing equality of entry conditions for both groups in relation to previous exposure to the words and ensure that the acquisition of these new words, if it occurs, is due to experimental manipulation, rather than to some additional exposure (Horst, Parsons, \& Bryan, 2011).

Another important factor in vocabulary learning from shared reading is the type of learning measure used in the studies. Most studies usually use matching-to-sample tasks: with the unknown word said to the child (the unfamiliar word that appears in the story), who is asked to select one of the objects/figures arranged in front of him/her (McLeod \& McDade, 2011; Wilkinson \& Houston-Price, 2013). This type of task evaluates the listening behavior of children. Other studies (Hassinger-Das et al., 2016) have also employed expressive measures (speaker repertoire), in which the child is asked to name new figures or objects, whose names have appeared throughout the story. However, considering the difficulty of indicating the exact moment when an unfamiliar word becomes well known, and the familiarity between new words and well-known words (Horst, 2013), it is necessary to consider that the learning of new words includes a series of different repertories and complexities (Garcia, Vaz, \& Schmidt, 2016). Therefore, in addition to the tasks commonly used in studies on the subject (matching-to-sample and naming probes), this study also investigated the learning of new word-figures relations using responding by exclusion probes (in which the child selects the figure of a completely new, unknown object, having as comparisons, as well as that figure, the figures of undefined objects present in the story) (Dixon, 1977), probes of description of the use of undefined objects present in the story, and generalization probes (probes of pairing with the undefined objects themselves).

Thus, the aim of this study was to investigate the learning of new word-figure relations in a shared book reading situation, comparing the performances of children aged 
3 and 7 years and the possible occurrence of the Matthew Effect, using pseudowords as target stimuli and evaluating distinct repertories and different complexities as measures of new word-figure relations.

\section{Method}

\section{Participants}

Ten children aged 3 years (mean age: 36.5 months, SD: 2.8 months, 31-40 months) from two philanthropic schools of Childhood Education of the city of Ribeirão Preto - SP and 10 children aged 7 years (mean: 87 months, SD: 7.4 months, 75-98 months) were recruited using convenience sampling. Those responsible for the participants were informed about the study, and the authorization for the participation of the children was requested through signing of an informed consent form. The inclusion criteria in the sample, in addition to the respective ages, was the absence of indications of developmental delay, measured by the Denver II Screening Test, adapted for Portuguese (Pedromônico, Bragatto, \& Strobilus, 1999) in 3-year-old children and absence of reports of developmental delay in the 7-year-old children.

\section{Instruments}

A storybook and a book of tests were produced. The illustrations were made from photos of scenarios arranged according to the content of the story (Figure 1A). The images were treated and edited to highlight the undefined objects and to make them more similar to typical illustrations of children's books (Horst et al., 2011).

Throughout the story, four undefined nouns were presented (invented words): "Nezaca" (I1), "Vanito" (I2) "Fulito" (I3), and "Pafile" (I4). The pseudowords were composed of consonants that3-year-olds are, on average, able to produce (Wertzner, 2009). Two undefined objects ("Nezaca" and "Fulito") had some specific use, which was defined in the context (e.g. "I will get my fulito to store the crayon"). Each pseudoword was presented, separately from the others, three times in the story.

The book of tests consisted of 22 pages. The first two pages contained only figures of defined objects (images of common toys, four per page). Pages 3 and 4 contained figures of defined and undefined objects mixed (Figure 1B) and the next two pages contained images of the four undefined objects presented in the story. In the next two pages (7 and 8), three figures of undefined objects that appeared in the story and a completely new undefined object were presented (I5"Tofema" and I6- "Muvipo" - Figure 1C). The position of all the undefined figures was balanced between the quadrants, as well as the distribution of the correct responses $(\mathrm{S}+)$. The final 14 pages of the book of tests contained individual alternating images of defined (common toys) and undefined objects (I1 to I6).

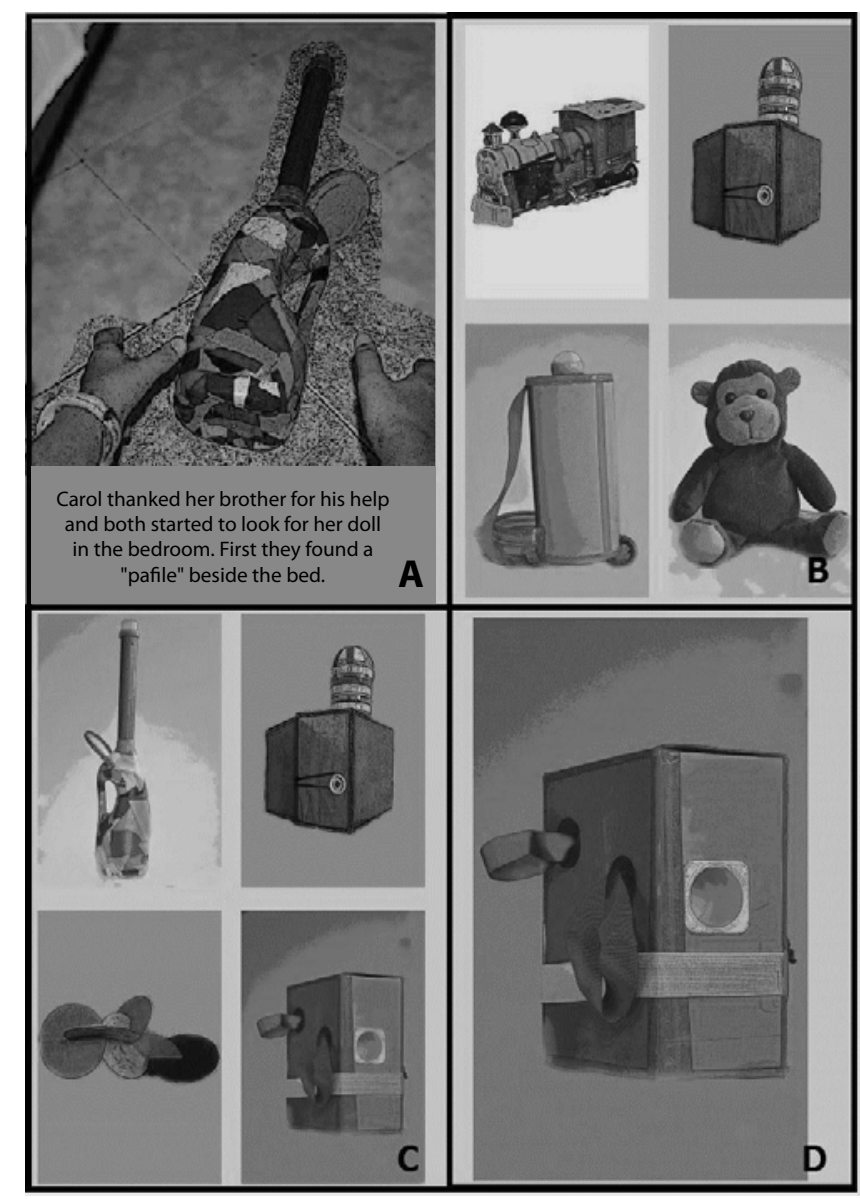

Figure 1. A - Example of a page from the storybook; B Example of a page from the book of tests; $\mathrm{C}$ - Example of a page from the book of tests, where the task was to verify the performance by exclusion given a matrix of choices that contained a completely new stimulus and the undefined stimuli presented in the story; D - Example of a page from the naming and description of use trials

\section{Procedure}

Data collection. Two experimental sessions were carried out: (1) reading of the storybook and learning tests and (2) maintenance tests. The (1) consisted of reading the story and learning tests (matching-to-sample, exclusion, naming and description of the use of the object probes), and (2) consisted of maintenance tests (learning tests plus the generalization probes). The second session occurred seven days after the first one.

(a) Session 1. The story was read to each child individually three consecutive times. The illustrative images of each part of the story were presented to the child following the reading. Possible questions from the children about the story were answered with the following phrase: "Let's see what happens now?". At the end of the first and second reading, the researcher said, "Shall we read it again?". After the readings, the learning tests started, using the book of tests. The first four trials (book of tests, p. 1 and 2, two trials for each page) were to understand the task: the name of a well-known object was dictated and 
the child was asked to indicate (by gluing an adhesive on top) which of the figures on the page of the book corresponded to the word (e.g. the researcher would say: "Glue this over the figure of the ball," and the child would stick the adhesive on the figure of the ball). Correct responses were followed by compliments, such as "Congratulations!", "You're right!". If the child failed to make the right choice, the researcher would present a correction trial on the same page of the book, saying, for example: "No, that's not the figure of the ball. Let's try again? Show me the figure of the airplane". If the child failed three consecutive trials (including the correction trials), the task was terminated, the child was conducted back to the class, and his/her data were excluded from the analysis.

The next four trials were matching-to-sample probes (book of tests, pages 3 to 6) and the child should again glue an adhesive over the pictures corresponding the words stated. The purpose of these trials was to verify whether the child could identify the figure corresponding to the undefined word presented in the story. The researcher asked: "Where is the fulito?", and the child should indicate the corresponding image of the undefined object "fulito" from among the options available. From these trials onwards, the child received no feedback from the researcher and the trial ended with the researcher saying "Let's turn the page?".

Two exclusion probes were then presented (book of tests, pages 7 and 8): a completely unknown pseudoword was dictated and there was a completely new undefined object (I5 or I6) among the alternatives, as well as the three that had been presented in the story. The purpose of this task was to verify whether the learning process of the undefined name-figure relations was established in a way the child was able to respond by exclusion given a matrix of choices that contained the undefined stimuli presented in the story and another completely new stimulus.

Then the naming and description probes were presented (book of tests, last 14 pages). The purpose of these trials was to verify whether the participant would name and/or describe some feature regarding the use of the undefined objects. Individually, the figures of defined and undefined objects were presented, and the researcher asked: "What is the name of this? Do you know what that is for?". The child's task was to say the name and utility of the objects presented.

At the end of this session, the researcher played for more five minutes with the child, in the case of the 3-year-olds, and conducted them back to the class. With the 7-year-olds, the researcher talked about various subjects for five minutes and released them to play with their friends.

(b) Session 2. In this session, the same learning tests were shown, and the generalization probes were conducted at the end of the other probes. The purpose of the generalization probes was to verify whether the child would select the threedimensional objects corresponding to the figures that appeared in the story. Eight objects (six objects designed for the study and two well-known toys) were arranged on the floor side by side and in front of the child. The researcher requested: "Get the nezaca for me". After taking the object that was delivered by the child, the researcher would return it to the same position it was before and request the next object. Two well-known toys and four objects corresponding to the undefined names presented in the story were requested, totaling six trials for each participant.

At the end of each session, the researcher thanked the child and praised his/her attention and collaboration.

Data analysis. Responses to the probes were recorded on a registration sheet and in the books of tests itself (sticker glued by the children). All the sessions were filmed, guaranteeing the registration of naming, description of use and generalization tasks, which were then compared with the record of the researcher. Incorrect and correct responses were computed. A second observer assisted in approximately $30 \%$ of the filming of sessions by recording naming, description of use and generalization performances. The reliability index between the observers was calculated and its score was $100 \%$. For the quantitative analysis, a Chi-squared test was used to evaluate whether there were differences in performance in each type of probe between the first and second experimental session. The same test was used to verify whether there were differences regarding the variable "use of the undefined object". Both age groups were compared for the different learning measures using the Mann-Whitney U Test for independent samples. All analyses were performed in the Bioestat 5.3 program.

\section{Ethical Considerations}

ThisstudywasapprovedbytheResearchEthics Committee with Human Subjects (CAAE 19044013.0.0000.5407), and all the parents signed an informed consent form.

\section{Results}

Based on the errors and correct responses of the participants of both age groups, the data were initially grouped by correct responses for the undefined nouns presented with and without use, both in the first and second experimental sessions. In the Chi-squared test, no statistically significant differences were found between correct responses related to the pseudoword with and without a specific use defined in the story ( $p=0.45$ in the first session, $p=0.21$ in the second experimental session). Thus, the correct responses and errors were grouped without considering if the words had a defined function, and it was possible to evaluate whether there were differences between the performances in the first and second experimental sessions. No significant difference was found $(p=0.46)$.

After these initial analyses, the responses to the matching probes were used as repeated measures for each participant and the performances between the two age groups were compared using the Mann-Whitney Test for independent samples. The same was done for the exclusion and generalization tasks. No significant difference was found between the groups in the matching-to-sample $(p=0.33)$ and generalization $(p=0.38)$ probes; however, in the exclusion tasks, a significant difference was found between the two age groups $(p=0.0004)$, as seen in Figure 2 . 


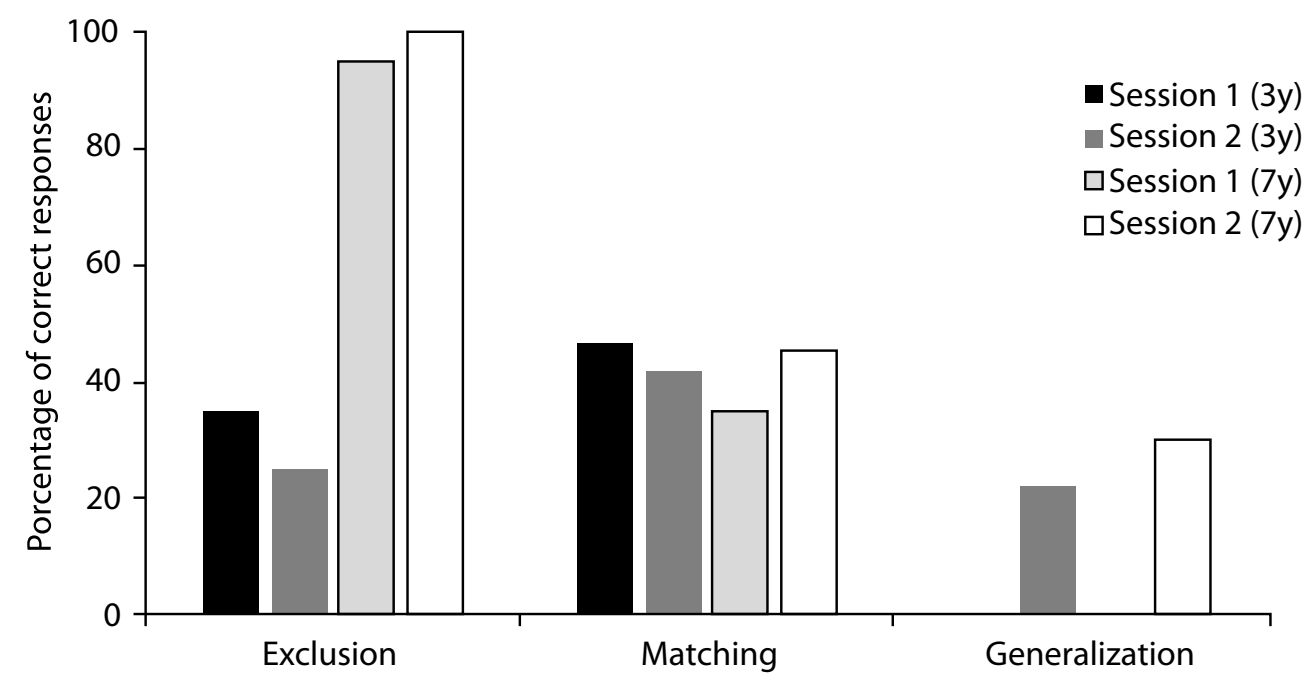

Figure 2. Percentage of correct responses for each age group (3y and 7y) in each type of learning probe, in Session 1 (learning probes) and in Session 2 (maintenance).

All the children responded adequately to the probes of naming and description of the function of the known stimuli (common toys), in both experimental sessions. Only four participants named the undefined objects correctly, and all of them belonged to the 7-year-old group. Each child correctly named only one undefined figure: two of them (P74 and P78) named it Fulito, and another (P71) Pafile in the first experimental session; Only P73 named it Pafile in the second experimental session.

The other children were silent when presented with the figures of undefined objects or gave answers such as "I don't know" or "I don't remember". Some, possibly under the control of the physical aspects of the undefined objects, assigned them names of defined objects (e.g. "box," "house," "backpack"). Other participants created their own undefined nouns for the objects presented during the reading. This last description included P72 and P74, who used the pseudoword "Fulito" to name another undefined object. It is worth noting that P74 used this same pseudoword for all the undefined objects.

No 3-year-old participant described the use of the undefined objects as presented in the story. In this age group, the responses of two participants stood out. The first, P34, presented an adequate ("for playing"), although broad, response for the use of the object, indicating that the child was not under the control of the specific use presented in the story, but of the general context, since all the stimuli could be described as toys. The second participant, P37, gave answers referring to elements presented in the story that had close relationships with the stimulus in question ("crayon," for the object used to store crayons in the story, and "has the doll inside," for the object that, in the story, was used to store the doll).

Overall, the 7-year-olds described better the use of the objects presented in the story, discriminating that some of the objects were toys and that others had other additional functions. In this group, three of the 10 participants (P70, P71 and P78) correctly described the use of the two undefined objects in both experimental sessions. Another participant (P77) also responded correctly in the first and second experimental sessions, but only one of the undefined objects. We also observed that four participants (P72, P73, P74 and P76) described the use of one of the undefined objects according to what was presented in the story during the first experimental session, and only one participant gave the same answer in the second experimental session. Participants P73 and P75 assigned the use of I 2 to I1 and vice versa.

\section{Discussion}

This study aimed to investigate the learning of pseudowords through story reading by children of different age groups ( 3 and 7 years old), using different learning measures. The children of both groups had similar results except in the exclusion probes, and the allegedly higher vocabulary level of the 7-year-old children was not a sufficient condition for more effective learning of pseudowords, indicated by the results of the matching probes.

Considering only the results of the matching probes, it is possible to say that the Matthew Effect was not found in this study. These data are different from those found in some studies on vocabulary learning in shared reading situations (Robbins \& Ehri, 1994; Sénéchal et al., 1995). In these studies, the children assessed with a higher level of vocabulary (generally using the Peabody Pictures Vocabulary Test - PPVT) did better in the multiple choice tests (similar to the matching probes presented here) than those children with lower vocabulary level. Perhaps the key to understanding the incidental learning of vocabulary (such as shared book reading) is to consider that learning words and their relationship with objects, events, and with the world is a continuous process involving a series of interrelated repertoires (Horst, 2013), which does not completely occur from a small number of exposures, such as a book reading episode. 
Studies that document the Matthew Effect in learning new words from shared book reading have in common the use, although unfamiliar, of commonplace words. Children with greater vocabulary probably live in verbally richer environments (Hart \& Risley, 1995) and therefore have more contact not only with a wider variety of words but with more opportunities to speak and interact with adults. Although in the initial tests these children did not correctly select the figures related to the words in the story, it is possible they already had some previous contact with these words, which could be a facilitating factor in learning "new" vocabulary.

Conversely, it is possible that studies that do not document the Matthew Effect using unfamiliar yet current words use strategies that guarantee, even for the children with lower vocabulary levels, sufficient contact with new words and figures. This is what may have occurred in the study by Walsh and Blewitt (2006), who used a dialogic reading strategy with different types of questions related to the target words and compared it with a group in which the reading was performed without this strategy. Their results showed difference between the experimental groups and the control group, but it did not indicate any effect of the previous vocabulary of the participant in learning new words. In this case, it is possible the experimental manipulation (asking questions during reading) surpassed any possible effect of the previous vocabulary of the participants. The interactions between the researcher and the children may have promoted a greater number of S-S pairing (between the words and their referents), favoring learning (Sousa, Souza, \& Gil, 2013). A similar situation occurred in the study by HassingerDas et al. (2016), who used a "word game" with children as a complementary strategy to reading, or in the study by Pollard-Durodola et al. (2011), in which an intensive story reading intervention was conducted with the children, ensuring a number of opportunities for the children to be in contact with unfamiliar vocabulary.

The results obtained in this study support the idea that the Matthew Effect is a result of the previous learning history of the children, since the children of very different ages (and consequently with different levels of vocabulary and language acquisition), when exposed to completely new words (pseudowords), had the same performance in most learning probes. In addition, these results also support the idea that learning new words is a continuous process and involves several conditions, such as frequency and contexts of exposure to the word (Horst, 2013).

Assuming that learning the relationships between words and their referents requires a continuum of repertoires, different probes were presented to evaluate the learning process in performances that required different degrees of complexity. In the exclusion probes, we evaluate a fairly basic level of learning: to discriminate completely new pseudowords and undefined figures, from unfamiliar pseudowords and figures, which had already appeared in the story. For this performance (of exclusion) (Dixon, 1977; Schmidt, 2016), it would be necessary for the unknown words/figures that appeared in the story to be established previously, through readings, as a minimally consistent baseline that would ensure the formation of two classes of stimuli: the "well known" (that appeared in the story) and the "unknown" (the new words/figures) (Costa, de Rose, \& de Souza, 2010).

This performance was presented by the older children and not by the younger ones. The younger children had more difficulty establishing a "stimulus class that appeared in the story." On the other hand, the older children had more opportunities to learn a series of relationships between environmental stimuli, with greater learning experience to make relationships leading to a greater ability to think or act in a more abstract way (de Rose \& Rabelo, 2012). Forming stimulus classes is an "symbolic" behavior older children have, precisely because of this greater experience in learning relations between stimuli. Thus, the incidental exposure to pseudowords during reading was sufficient for older children to form this initial class of "undefined stimuli"; however, it was not enough for the younger children, who needed more direct teaching of such relations or more frequent exposure to them (Schmidt, Franco, Lotério, \& Gomes, 2016).

Good performance in exclusion probes did not necessarily lead to consistent learning of a name-object relation, as seen in the results of the matching, generalization and naming probes, and by a number of other literature studies (Antoniazzi, Domeniconi, \& Schmidt, 2014; Costa et al., 2010; Costa, Grisante, Domeniconi, de Rose, \& de Souza, 2013; Schmidt et al., 2016). These results suggest that the learning (in its different forms) of completely new relationships between words and their referents (figures, objects, properties of objects and relationships) depends on a series of conditions and a varying number of contexts of exposure. Taking the naming performance as an example: the results of the participants in this study in the naming probes, even those of the older children, indicate that this is possibly the most complex task when learning a new relationship between a word and its referent and that it is one of the last verbal repertoires acquired in the complete learning of this relationship.

Authors such as Greer (Greer \& Du, 2015; Greer \& Longano, 2010) argue that naming (in its broadest sense) is a crucial stage in the verbal development of children, and it allows them toward incidental language learning. Naming is the fusion or integration of the speaker and listener repertoires (Greer \& Longano, 2010; Skinner, 1957) and is a result from a set of multiple experiences that occur in the life of the child, so that, from everyday situations of exposure to new relations between words and their referents, the child would learn, without direct teaching, multiple new words (e.g. orienting toward the object upon hearing the word, following a statement in which the word is presented) or to the objects (e.g. saying the name of the object, using it properly, or even saying what it is for, as in the probes describing the use of the objects conducted in this study). For this integration of repertoires to occur, the child must be exposed to different situations involving the word. These multiple situations are provided in specific interventions with children with delayed language development (multiple exemplar instruction - MEI) (Greer \& Du, 2015); however, 
Vaz, A. M., \& Schmidt, A. (2019). Learning of Pseudowords and Shared Book Reading.

they also occur in everyday situations, when the child is exposed to the pairing between the object and its name (e.g. when the adult points to a dog on the street and says: "Look at the dog!" - ostensive pairing): Sousa et al. (2013), or when the adult says a word and the child repeats it (echoic): Souza, Almeida-Verdu, Bevilacqua (2013) and Skinner (1957), among several other situations.

This means that the incidental learning of new words stems from a set of previous experiences in the child's life (which may have been captured in studies that assess the Matthew Effect in vocabulary learning or in story reading), which do not teach them only specific relationships between words and certain aspects of the world, but teach them "how to learn." However, the specific conditions present in the incidental teaching situation, such as the amount of exposure to the target words, or the form of exposure, are also critical (Costa et al., 2013), with these aspects having been broadly investigated in different studies.

The results presented here need to be weighed against some methodological limitations of the study, such as the lack of a prior formal measure of the vocabulary of the participants, the number of target stimuli, and the number of trials in the matching probes. The studies that report the occurrence of the Matthew Effect in vocabulary learning (Robbins \& Ehri, 1994; Sénéchal et al., 1995) previously evaluated the current vocabulary of their participants, unlike this study, in which the differences in vocabulary levels were presumed to be a function of age. Another point to consider is the number of target words presented: learning four pseudowords by reading stories is not an easy task, even for older children. However, that choice favored the investigation of the Matthew Effect. Other studies on vocabulary learning by children from shared book reading indicate that even a very young child can learn at least two new word-figure relations (Garcia et al., 2016; Wilkinson \& Houston-Price, 2013). It was therefore considered that a very small number of new words could generate a very easy learning situation for both groups, hindering the intended comparison.

Finally, due to the long tradition of this type of study by researchers in the field of Psycholinguistics and Cognitive Psychology, it is noteworthy that this study investigated verbal behavior considering the basic principles proposed by Behavior Analysis. Thus, the theoretical contribution of Behavior Analysis for this type of investigation is highlighted. This approach has traditionally investigated issues related to the formation and maintenance of stimulus classes in isolated, unnatural experimental tasks, or very specific aspects of verbal behavior (e.g. learning and the occurrence of the mand and tact functional classes). The body of knowledge accumulated by Behavior Analysis can help understand the functions of the verbal operants and the formation process of stimulus class in more natural situations, such as storyreading contexts. Considering that verbal behavior has been the subject of studies by authors from different disciplines and theoretical orientations, who emphasize the role of culture in the emergence and development of verbal behavior (Skinner, 1957; Tomasello, 2003; Vygotsky, 1989) and considering that story reading is present in different cultures (Bus et al., 2000; Farrant \& Zubrick, 2013; Zucker et al., 2013), similar studies are important to understand the phenomena related to language acquisition and development.

\section{References}

Antoniazzi, M., Domeniconi, C., \& Schmidt, A. (2014). Efeito da pré-exposição ao objeto no desempenho por exclusão e na aprendizagem da relação nome-objeto [Effect of object pre-exposure on exclusion performance and nameobject relation learning]. Acta Comportamentalia, 22(1), 23-36. Retrieved from http://pepsic.bvsalud.org/scielo. php?script=sci_arttext\&pid=S0188-81452014000100003

Blewitt, P., \& Langan, R. (2016). Learning words during shared book reading: The role of extratextual talk designed to increase child engagement. Journal of Experimental Child Psychology, 150, 404-410. doi:10.1016/j.jecp.2016.06.009

Bus, A. G., Leseman, P. P., \& Keultjes, P. (2000). Joint book reading across cultures: A comparison of SurinameseDutch, Turkish-Dutch, and Dutch parent-child dyads. Journal of Literacy Research, 32(1), 53-76. doi: 10.1080/10862960009548064

Costa, A. R. A., de Rose, J. C., \& de Souza, D. G. (2010). Interferência de variáveis de contexto em sondas de exclusão com substantivos e verbos novos [The interference of contextual variables on exclusion probes of novel names and verbs]. Acta Comportamentalia, 18(1), 35-54. Retrieved from http://pepsic.bvsalud.org/scielo. php?script=sci_arttext\&pid=S0188-81452010000100003

Costa, A. R. A., Grisante, P. C., Domeniconi, C., de Rose, J. C. C., \& de Souza, D. G. (2013). Naming new stimuli after selection by exclusion. Paidéia (Ribeirão Preto), 23(55), 217-224. doi:10.1590/1982-43272355201309

de Rose, J. C. C., \& Rabelo, L. Z. (2012). Teoria das molduras relacionais e possíveis aplicações à educação [Relational frame theory and possible applications for education]. DI- Revista de Deficiência Intelectual, 2(3), 10-15. Retrieved from http://www.apaesp.org.br/pt-br/sobredeficiencia-intelectual/publicacoes/PublishingImages/ revista-di/artigos_pdf/DI-N3.pdf

Dixon, L. S. (1977). The nature of control by spoken words over visual stimulus selection. Journal of the Experimental Analysis of Behavior, 27(3), 433-442. doi:10.1901/jeab.1977.27-433

Duff,D., Tomblin,J.B., \& Catts,H.(2015).Theinfluence ofreading on vocabulary growth: A case for a Matthew effect. Journal of Speech, Language, and Hearing Research, 58(3), 853-864. doi:10.1044/2015_JSLHR-L-13-0310

Farrant, B. M., \& Zubrick, S. R. (2013). Parent-child book reading across early childhood and child vocabulary in the early school years: Findings from the longitudinal study of Australian children. First Language, 33(3), 280293. doi: $10.1177 / 0142723713487617$ 
Fontes, M. J. O., \& Cardoso-Martins, C. (2004). Efeitos da leitura de histórias no desenvolvimento da linguagem de crianças de nível sócio-econômico baixo [Effects of story reading on low SES children's language development]. Psicologia: Reflexão e Crítica, 17(1), 83-94. doi:10.1590/ S0102-79722004000100011

Garcia, F. P., Vaz, A. M., \& Schmidt, A. (2016). Shared book reading and word learning in preschool children. Temas em Psicologia, 24(4), 1437-1449. doi:10.9788/TP2016.414En

Greer, R. D., \& Du, L. (2015). Identification and establishment of reinforcers that make the development of complex social language possible. International Journal of Behavior Analysis \& Autism Spectrum Disorders, 1(1), 13-34.

Greer, R. D., \& Longano, J. (2010). A rose by naming: How we may learn how to do it. The Analysis of Verbal Behavior, 26(1), 73-106. doi:10.1007/BF03393085

Hart, B., \& Risley, T. R. (1995). Meaningful differences in the everyday experience of young American children. Baltimore, MD: Brookes.

Hassinger-Das, B., Ridge, K., Parker, A., Golinkoff, R. M., Hirsh-Pasek, K., \& Dickinson, D. K. (2016). Building vocabulary knowledge in preschoolers through shared book reading and gameplay. Mind, Brain, and Education, 10(2), 71-80. doi:10.1111/mbe.12103

Hindman, A. H., Skibbe, L. E., \& Foster, T. D. (2014). Exploring the variety of parental talk during shared book reading and its contributions to preschool language and literacy: Evidence from the Early Childhood Longitudinal Study-Birth Cohort. Reading and Writing, 27(2), 287313. doi:10.1007/s11145-013-9445-4

Horst, J. S. (2013). Context and repetition in word learning. Frontiers in Psychology, 4, 149. doi:10.3389/ fpsyg.2013.00149

Horst, J. S., Parsons, K. L., \& Bryan, N. M. (2011). Get the story straight: Contextual repetition promotes word learning from storybooks. Frontiers in Psychology, 2, 17. doi:10.3389/fpsyg.2011.00017

McLeod, A. N., \& McDade, H. L. (2011). Preschoolers' incidental learning of novel words during storybook reading. Communication Disorders Quarterly, 32(4), 256-266. doi:10.1177/1525740109354777

Pedromônico, M. R. M., Bragatto, E. L., \& Strobilus, R. (1999). Teste de Triagem Denver II. São Paulo, SP: UNIFESP.

Pollard-Durodola, S. D., Gonzalez, J. E., Simmons, D. C., Kwok, O., Taylor, A. B., Davis, M. J., ... Simmons, L. (2011). The effects of an intensive shared bookreading intervention for preschool children at risk for vocabulary delay. Exceptional Children, 77(2), 161-183. doi:10.1177/001440291107700202
Robbins, C., \& Ehri, L. C. (1994). Reading storybooks to kindergartners helps them learn new vocabulary words. Journal of Educational Psychology, 86(1), 54-64. doi:10.1037/0022-0663.86.1.54

Schmidt, A. (2016). "Esse não é um pitilics, então só pode ser aquele": O responder por exclusão e a aprendizagem de repertórios verbais [This is not a pitilics, then it can only be that": Responding by exclusion and the learning of verbal repertoires]. In P. G. Soares, J. H. Almeida, \& C. R. X. Cançado (Orgs.), Experimentos clássicos em análise do comportamento (pp. 171-185). Brasília, DF: Instituto Walden4.

Schmidt, A., Franco, M. G. O., Lotério, L. S., \& Gomes, G. F. (2016). Learning name-object relations after a single exclusion trial in 18-to 48-month-old children. The Psychological Record, 66(1), 53-63. doi:10.1007/s40732-015-0151-2

Sénéchal, M., Thomas, E., \& Monker, J. (1995). Individual differences in 4-year-old children's acquisition of vocabulary during storybook reading. Journal of Educational Psychology, 87(2), 218-229. doi:10.1037/0022-0663.87.2.218

Skinner, B. F. (1957). Verbal behavior. New York, NY: Appleton-Century-Crofts.

Sousa, N. M., Souza, C. B. A., \& Gil, M. S. C. A. (2013). Aprendizagem rápida de comportamento de ouvinte por um bebê [Rapid listener behavior learning by an infant]. Interação em Psicologia, 17(1), 67-78. doi:10.5380/psi. v17i1.28205

Souza, F. C., Almeida-Verdu, A. C. M., \& Bevilacqua, M. C. (2013). Ecoico e nomeação de figuras em crianças com deficiência auditiva pré-língual com implante coclear [Echoic and picture naming in prelingual impaired hearing children with cochlear implant]. Acta Comportamentalia, 21(3), 273-283. Retrieved from http://pepsic.bvsalud.org/scielo.php?script=sci arttext\&pid=S0188-81452013000300004

Stanovich, K. E. (1986). Matthew effects in reading: Some consequences of individual differences in the acquisition of literacy. Reading Research Quarterly, 21(4), 360-407. doi:10.1177/0022057409189001-204

Tomasello, M. (2003). Origens culturais da aquisição do conhecimento humano [The cultural origins of human cognition] (C. Berliner, Trans.). São Paulo, SP: Martins Fontes.

Vitto, M. M. P., \& Feres, M. C. L. C. (2005). Distúrbios da comunicação oral em crianças [Oral communication disturbances in children]. Medicina (Ribeirão Preto), 38(3-4), 229-234. doi:10.11606/issn.2176-7262. v38i3/4p229-234

Vygotsky, L. S. (1989). Pensamento e linguagem [Thought and language] (J. L. Camargo, Trans., 2nd ed.). São Paulo, SP: Martins Fontes. 
Walsh, B. A., \& Blewitt, P. (2006). The effect of questioning style during storybook reading on novel vocabulary acquisition of preschoolers. Early Childhood Education Journal, 33(4), 273-278. doi:10.1007/s10643-005-0052-0

Wertzner, H. F. (2009). Fonologia: Desenvolvimento e alterações [Phonology: Development and change]. In L. P. Ferreira, D. M. Befi-Lopes, \& S. C. O. Limongi (Eds.), Tratado de fonoaudiologia (pp. 772-786). São Paulo, SP: Roca.

Wilkinson, K. S., \& Houston-Price, C. (2013). Once upon a time, there was a pulchritudinous princess ... : The role of word definitions and multiple story contexts in children's learning of difficult vocabulary. Applied Psycholinguistics, 34(3), 591-613. doi:10.1017/ S0142716411000889

Zucker, T. A., Cabell, S. Q., Justice, L. M., Pentimonti, J. M., \& Kaderavek, J. N. (2013). The role of frequent, interactive prekindergarten shared reading in the longitudinal development of language and literacy skills. Developmental Psychology, 49(8), 1425-1439. doi:10.1037/a0030347

Aline Melina $\mathrm{Vaz}$ is a doctoral student of the Faculdade de Filosofia, Ciências e Letras de Ribeirão Preto at the Universidade de São Paulo, Ribeirão Preto-SP, Brazil.

Andréia Schmidt is a Professor of the Faculdade de Filosofia, Ciências e Letras de Ribeirão Preto at the Universidade de São Paulo, Ribeirão Preto-SP, Brazil.

Authors' Contribution:

All authors made substantial contributions to the conception and design of this study, to data analysis and interpretation, and to the manuscript revision and approval of the final version. All the authors assume public responsibility for content of the manuscript.

Received: Jul. 27, 2017

1st Revision: Nov. 28, 2017

2nd Revision: Jan. 29, 2018

Approved: Mar. 02, 2018

How to cite this article:

Vaz, A. M., \& Schmidt, A. (2019). Learning of pseudowords by children of different ages in a shared book reading context. Paidéia (RibeirãoPreto), 29, e2912. doi: http://dx.doi.org/10.1590/1982-4327e2912 